\title{
METODOLOGÍA PARA MEDIR LA ESTRUCTURA URBANA DE LA CIUDAD ACTUAL, UTILIZANDO LA BASE DE DATOS DEL CATASTRO. APLICACIÓN AL SECTOR SUROESTE DE LA COMUNIDAD DE MADRID*
}

\author{
José Miguel Santos Preciado \\ Universidad Nacional de Educación a Distancia \\ jsantos@geo.uned.es
}

\section{RESUMEN}

La realidad de nuestras grandes urbes muestra como la ciudad compacta se está transformando en una ciudad cada vez más dispersa y fragmentada, con periferias más extensas y límites más difusos. La dispersión de la ciudad por el territorio ha estado acompañada, en general, de cierta pérdida de su tradicional complejidad, debido a la similitud funcional y separación espacial de las diversas partes que conforman su estructura urbana.

En este contexto, el uso del catastro de urbana, como repositorio de datos espaciales, resulta de gran interés en la investigación funcional de la ciudad actual. El trabajo que presentamos tiene como objetivo definir una metodología aproximativa a la identificación tipológica de unidades estructurales básicas de la ciudad dispersa, a partir de la combinación potencial de los usos del suelo existentes en cada parcela catastral.

Palabras clave: Cartografía catastral; Sistemas de Información Geográfica; Estructura urbana; Desarrollo urbano.

Fecha de recepción: noviembre 2012.

Fecha de aceptación: junio 2013.

* Este artículo ha sido elaborado, como trabajo preliminar del proyecto de investigación: «Análisis de la dinámica urbana actual, utilizando bases de datos geográficas de detalle. Aplicación al diseño de escenarios a escala subregional, en la elaboración de modelos de simulación» (CSO2012-38158-C02-02), financiado por el Ministerio de Economía y Competitividad, cuyo investigador principal es José Miguel Santos Preciado. 


\section{ABSTRACT}

The reality of our big cities shows how the compact city is being transformed into a city always more disperse and fragmented, with more extensive outskirts, and more diffuse limits. The scattering of the city through the territory has been accompanied, in general, with a certain loss of its traditional complexity, due to the functional similarity and the spatial separation of the different parts which comprise its urban structure.

In this context, the use of the urban land registry as a repository of spatial data, is of great interest in the functional investigation of the modern city. The work that we present aims to define a methodology that approximates to the typological identification of basic structural units of the scattered city, starting from the potential combination of existing uses of each plot of land in the land registry.

Keywords: Cartography of the registry; Geographical Information Systems; Urban structure; Urban development.

\section{INTRODUCCIÓN}

La dispersión urbana ha llegado a consolidar, en el espacio geográfico de la Europa meridional, un nuevo modelo de ciudad (Monclús, 1998), caracterizado por una serie de rasgos propios que han transformado, profundamente, las características y tradicional localización relativa de los usos del suelo urbano. Entre los cambios más significativos podríamos destacar (Font et al., 1999):

a) El traslado de la residencia con un claro predominio de las bajas densidades y la tipología unifamiliar hacia territorios cada vez más distantes, por los elevados precios de la vivienda o, siguiendo al empleo descentralizado, convirtiendo las antiguas urbanizaciones de la segunda residencia en primera, y ocupando los nuevos barrios residenciales de los municipios metropolitanos más alejados.

b) La descentralización de la industria y del terciario de menor valor añadido, también hacia la periferia metropolitana, en el marco de las transformaciones en el sistema productivo y en las tecnologías de la telecomunicación.

c) La aparición de nuevas localizaciones del terciario y las grandes dotaciones polarizadas sobre la infraestructura arterial, como elementos emergentes de un nuevo paisaje metropolitano, superpuesto a los anteriores órdenes de la ciudad compacta o de la dispersión territorial.

d) Algunas operaciones de renovación interna (áreas de nueva centralidad) en las ciudades grandes y medianas, en las que el terciario y las dotaciones en general juegan un papel relevante.

e) La continuada pérdida e insularización de los espacios «naturales» (bosques, áreas agrícolas, riberas, etc.). 
Esta imagen, que refleja, con bastante exactitud, la realidad de nuestras urbes, concuerda con aquella otra que afirma que, durante los últimos años, estamos asistiendo a «la explosión de la ciudad sobre la región, de manera que las actividades económicas, la población y la vivienda se expanden y fluyen hacia las áreas rurales próximas» (Ferrás, 2000). Como consecuencia de este fenómeno, parques empresariales y de oficinas, polígonos industriales, parques tecnológicos, universidades, centros comerciales y de ocio, residencia de baja densidad de ocupación, etc., salpican con frecuencia el territorio metropolitano más alejado del centro de la ciudad, incrementando la sensación de paisaje fragmentario, discontinuo y desordenado. La descentralización progresiva de la población, los equipamientos y las empresas hacia la periferia, aparentemente caótica, se organiza, sin embargo, a través de una red viaria de gran capacidad, que actúa como elemento articulador del territorio de las nuevas periferias. Se trata, en realidad, del paso del «aglomerado a la red» (Dematteis. 1998), donde se privilegia la accesibilidad de los nodos, garantía de la rápida y eficaz interconexión con el resto de las actividades de la ciudad.

Este proceso de cambio se ha producido, paralelamente, a una profunda transformación de los elementos que componen la estructura urbana de las grandes ciudades. La organización territorial de la ciudad tradicional, caracterizada por la complejidad morfotipológica y la mezcla de usos del suelo, está dando paso a un nuevo territorio urbano, donde las formas espaciales emergentes destacan por el carácter especializado y frecuentemente monofuncional de los fragmentos que componen el nuevo mosaico de la ciudad actual (De Santiago, 2008). En realidad, se trataría de un complejo urbano discontinuo, caracterizado por la heterogeneidad morfológica y funcional de las diversas piezas urbanas que lo integran, a la par que por la homogeneidad dentro cada una de ellas.

El desarrollo urbano de las grandes ciudades de nuestro país y la configuración de su estructura más reciente no ha tenido lugar de forma brusca, sino progresiva, desde los primeros momentos de conformación del modelo metropolitano clásico hasta el modelo disperso actual. Font et al . (1999) diferencian, al respecto, cuatro patrones de cambio clave en la presente disposición de «la estructura polinuclear discontinua» de nuestras metrópolis, que han dejado su impronta sobre el territorio:

a) La expansión del núcleo central y de los núcleos históricos de la región metropolitana, con caracteres de continuidad espacial y promiscuidad de usos (residencial, industrial, servicios, etc.), resultado de procesos de extensión y densificación de las mallas existentes, que fueron característicos hasta principios de los años setenta del pasado siglo. Estos ensanches de los núcleos urbanos de la primera y segunda coronas metropolitanas aún están presentes en los principales municipios de las aglomeraciones urbanas españolas.

b) Las transformaciones por sustitución o reforma, o por reutilización de vacíos existentes, producidas principalmente en la ciudad central, pero con amplio eco en los núcleos principales metropolitanos.

c) Los nuevos emplazamientos o lugares de las actividades de la innovación o de la centralidad dispersa, en enclaves de alta accesibilidad o exposición visual, o a lo largo de los elementos principales de la infraestructura viaria y del transporte público. Las grandes superficies comerciales, los grandes equipamientos y dotaciones (hospitales, 
universidades, instalaciones deportivas, etc.), las sedes representativas de las principales empresas del sector de los servicios y de la producción, junto con los nuevos espacios productivos (parques de actividad, parques de empresas) y, excepcionalmente, algún asentamiento residencial de prestigio, formarían parte de estas nuevas geografías urbanas.

d) Finalmente, las formas del crecimiento disperso, tradicionalmente la edificación aislada de la segunda residencia, que además de seguir consumiendo importantes superficies del territorio metropolitano, se han convertido, en parte, en residencia permanente en los territorios próximos (Gutiérrez Puebla y García Palomares, 2007).

Es nuestra intención, en el trabajo que presentamos, mostrar la manera en que se podría analizar, a partir de la base de datos del catastro de urbana, en un entorno SIG, la dinámica urbana madrileña con la información georreferenciada disponible, integrada por las coberturas de distintas variables de ocupación del suelo.

Esta labor la hemos llevado a cabo en dos etapas. En la primera, hemos tratado de definir una tipología de unidades estructurales básicas, a partir de la combinación potencial de los usos del suelo existentes en cada parcela catastral. Esta fase de la investigación ha estado centrada en la elaboración y diseño de una metodología adecuada para la delimitación de unidades territoriales elementales, que, a modo de células individuales, permitiera detectar la heterogeneidad del territorio, respecto al modelo global de funcionamiento. La segunda etapa ha estado dirigida a la reconstrucción del patrón de unidades estructurales derivadas, a partir de las anteriores, mediante la integración contigua de unidades territoriales de similar contenido temático, de acuerdo a los patrones definidos anteriormente. No se trataría tanto, en nuestro caso, de reconstruir la estructura global de la región madrileña (que requeriría de un trabajo de investigación de más largo alcance) como de mostrar algunos ejemplos de los espacios o segmentos urbanos más característicos.

\section{LAS BASES DE DATOS CATASTRALES Y SU APLICACIÓN AL ESTUDIO DE LA ESTRUCTURA URBANA MADRILEÑA}

El éxito o fracaso de una investigación está relacionado, en buena parte, con la disponibilidad o no de una base de datos precisa, fiable y de calidad, lo suficientemente flexible como para alcanzar los objetivos propuestos en una escala espacial operativa. Así, hace relativamente poco tiempo, se ha puesto a disposición pública un volumen considerable de información georreferenciada, de especial interés para llevar a cabo diferentes tareas relacionadas con la aplicación de las Tecnologías de la Información Geográfica (TIG) en el análisis y evaluación de diferentes aspectos relacionados con el actual modelo territorial. En este sentido, el catastro de urbana, elaborado por la Dirección General del Catastro del Ministerio de Hacienda y Administraciones Públicas, dispone de una información de suficiente nivel de detalle y cualificación ${ }^{1}$ como para alcanzar un objetivo como el que nos proponemos. Como ya señalaban Lavastre y Más (2005), esta base de datos espaciales permite integrar

1 En nuestra investigación, hemos empleado la base de datos del catastro de urbana de la Comunidad de Madrid, disponible en 2009, cedido por la Dirección General del Catastro del Ministerio de Hacienda. 
en los estudios urbanos una orientación interesante por el alto valor explicativo de carácter geográfico que reúne la propiedad de los inmuebles. Pero no solo eso; la información catastral disponible constituye una fuente básica para abordar los estudios históricos del paisaje, de los usos del suelo y de la propiedad rústica y urbana (Urteaga, 2008). Dicho repositorio y sus unidades espaciales de referencia (principalmente la parcela catastral, aunque también la manzana, edificaciones correspondientes, polígonos y subparcelas) ha resultado fundamental en nuestra investigación, ya que contiene información muy variada de las unidades fiscales que integran (usos del suelo, complementado por las variables de superficie ocupada, superficie edificada, momento de la construcción, etc.).

El catastro se organiza a partir de la parcela catastral, como unidad básica de gestión, definida como «el terreno cerrado por una línea poligonal que delimita el ámbito espacial del derecho de propiedad de un propietario o de varios proindiviso» (Guimet Pereña, 2003). Es, por tanto, la unidad de tratamiento fundamental a la que se refieren los datos catastrales. Cada parcela se identifica, obligatoriamente, de forma unívoca, por una única referencia catastral ${ }^{2}$.

La utilización de la parcela catastral en los estudios urbanos encuentra su justificación al constituir un ente geográfico homogéneo, cuya naturaleza intrínseca se deriva de su particular relación con la propiedad, así como de su contenido, relativo a sus características morfológicas, temporales y funcionales. Los datos temáticos que contienen dichas unidades espaciales se refieren, tanto a variables de tipo físico, que atienden a las dimensiones de las parcelas, superficie del solar y tipo de parcela, como a variables morfológicas, relacionadas con las características particulares de la trama urbana, variables temporales, que reflejan los momentos de comienzo y finalización en la construcción de los edificios que integran cada parcela, y, finalmente, variables de tipo funcional, que responden al uso y destino de la edificación, de forma diferenciada para cada tipo de construcción ${ }^{3}$.

En nuestro caso, la parcela catastral se ha convertido en un elemento importante para el estudio e interpretación de la ciudad, al permitir relacionar su crecimiento con la estructura y morfología urbanas connaturales con el mismo. Con el fin de alcanzar el objetivo propuesto, hemos utilizado la cartografía catastral urbana del sector suroeste de la Comunidad de Madrid, integrado por los municipios ${ }^{4}$ metropolitanos del sur $^{5}$ y oeste ${ }^{6}$. La representación cartográ-

2 La referencia catastral de una parcela está formada por 14 caracteres. Los siete primeros son dígitos que se calculan a partir de las coordenadas UTM de su centroide, y los siete siguientes identifican la hoja de la cartografía catastral del municipio en que aquella se encuentra. Los distintos bienes inmuebles contenidos en una parcela tienen una referencia catastral individualizada, que se obtiene añadiendo a los catorce caracteres anteriores otros seis, cuatro para su numeración correlativa y dos reservados como caracteres de control.

3 Las categorías identificadas son las siguientes: Almacén-Estacionamiento; Residencial; Industrial; Oficinas; Comercial; Deportivo; Espectáculos; Ocio y Hostelería; Sanidad y Beneficencia; Cultural; Religioso; Obras de urbanización y jardinería; Suelos sin edificar; Edificio singular; Almacén agrario; Industrial agrario; Agrario.

4 La información catastral viene referida a nivel municipal.

5 Los municipios del sur de Madrid considerados han sido: Alcorcón, Arroyomolinos, Cubas, El Álamo, Fuenlabrada, Getafe, Griñón, Humanes, Leganés, Moraleja de Enmedio, Móstoles, Parla, Pinto, Torrejón de la Calzada, Torrejón de Velasco y Valdemoro.

6 Los municipios del oeste de Madrid considerados han sido: Boadilla del Monte, Brunete, Collado Villaba, Collado Mediano, Colmenarejo, El Escorial, Galapagar, Guadarrama, Las Rozas, Majadahonda, Pozuelo de Alarcón, San Lorenzo del Escorial, Torrelodones, Valdemorillo, Villanueva de la Cañada, Villanueva del Pardillo y Villaviciosa de Odón. 
fica de ambos conjuntos de manera separada, puede apreciarse en las figuras 1 y 2 , enmarcada su situación respecto a las principales vías de comunicación por carretera de la región.

Pese a las grandes posibilidades que ofrece este particular repositorio de datos, no cabe duda que la utilización de la parcela catastral en los estudios urbanos presenta determinadas limitaciones, derivadas de su propia especificidad. Entre las más importantes podríamos destacar las siguientes:

1. La clasificación catastral se fundamenta en la distinción entre bienes rústicos y urbanos. Sin embargo, la realidad incluye otras situaciones, como el suelo urbanizable, por lo que surgen dudas justificadas a la hora de acometer modificaciones catastrales a raíz de un cambio o modificación de planeamiento.

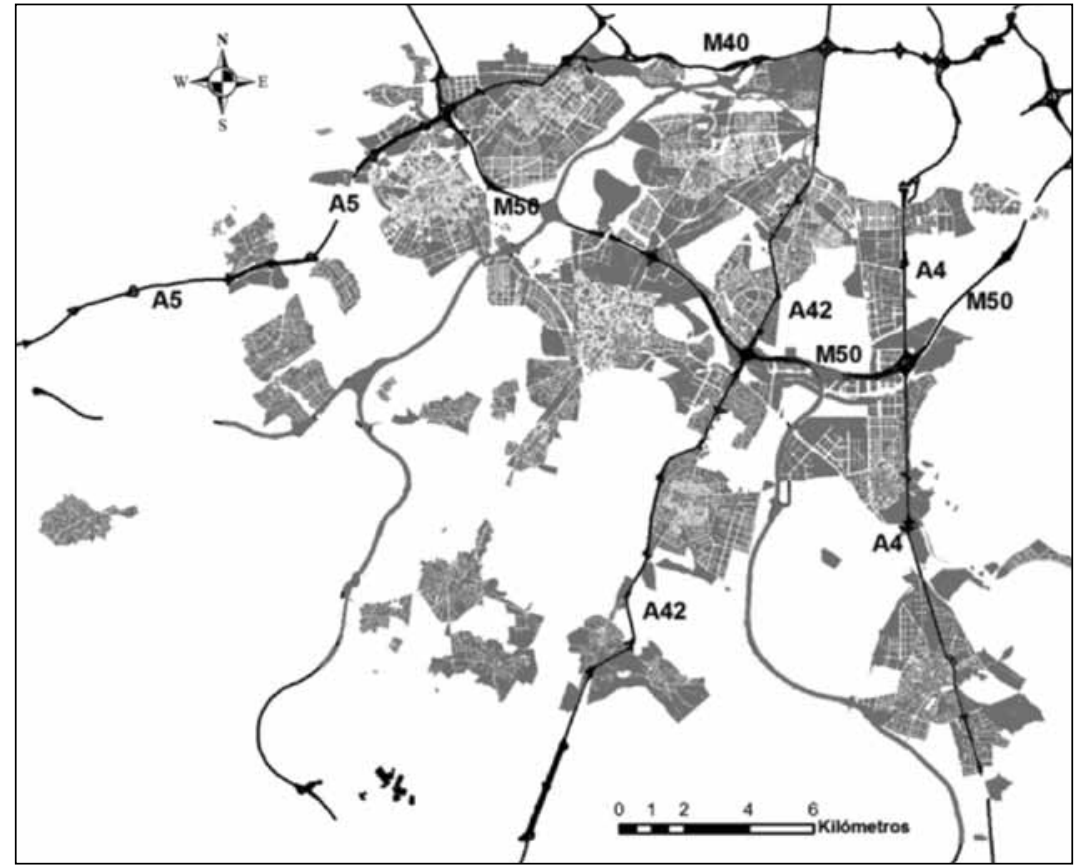

Fuente: Catastro de Urbana y Elaboración Personal.

2. La gestión de los catastros inmobiliarios rústico y urbano es complicada, al estar constituidos por un numeroso conjunto de datos y descripciones de los bienes inmuebles (superficie, situación, linderos, cultivos o aprovechamientos, calidades, valores y demás circunstancias físicas, jurídicas y económicas), que requieren de múltiples modificaciones diarias que deben ser puntualmente reflejadas. A pesar de la mejora introducida por el uso intensivo de las Tecnologías de la Información, mediante procedimientos automatizados, a partir de los Sistemas de Información Geográfica (SIG) 
(Sereno Álvarez, 2009), existen aún desfases en el reajuste de la información, que normalmente se halla dispersa entre distintas fuentes (Más Mayoral, 2009), lo que supone disponer, a veces, de bases de datos no completamente actualizadas.

3. Los procedimientos de gestión catastral demandan una fuerte interacción entre los datos alfanuméricos (tablas SIGECA) y cartográficos (cartografía digital SIGCA2). Sin embargo, ambos sistemas cuentan con mecanismos independientes de intercambio de datos. Esta circunstancia se refleja en la dificultad de ajustar la información cartográfica (en formato «shape») y la alfanumérica (formato CAT) en un SIG, lo que obliga a transformar esta última de forma que la información pueda ser manejada en un sistema informático común.

4. Finalmente, debemos remarcar que la parcelación urbana, concebida sobre la base del derecho de propiedad, implica la existencia de una heterogeneidad de tamaño del parcelario, lo que dificulta a veces el análisis de determinados fenómenos geográficos. Además, algunas categorías de los usos del suelo empleados incluyen mezcla de subcategorías, de relativa importancia, lo que complica la realización de análisis específicos sobre determinados servicios urbanos ${ }^{7}$.

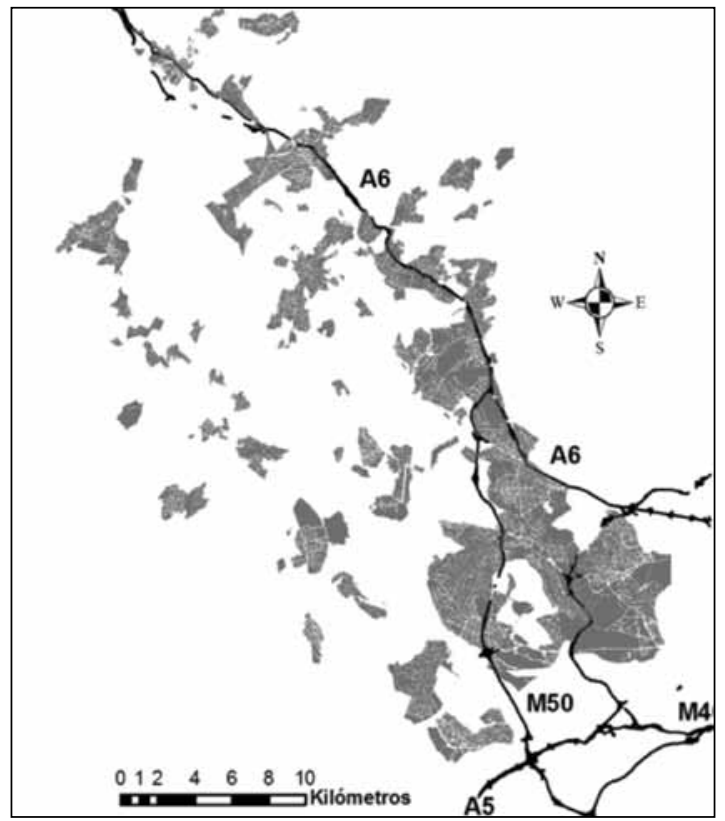

Fuente: Catastro de Urbana y Elaboración personal.

7 A modo de ejemplo, la categoría «cultural» contiene de forma conjunta tipos de inmuebles muy diversos, destinados a centros educativos de diferente nivel (universidades, institutos, centros de enseñanza primaria), iglesias, museos, etc. 


\section{DEFINICIÓN DE UNIDADES FUNCIONALES BÁSICAS EN LA AGLOMERACIÓN URBANA MADRILEÑA, A PARTIR DE LAS BASES DE DATOS CATASTRALES. CONTRASTES TERRI- TORIALES ENTRE EL SUR Y EL OESTE DE LA PERIFERIA DE LA COMUNIDAD DE MADRID}

La necesidad de una descripción renovada del territorio urbano está en la base de la reciente aparición de diversos estudios, que se nos ofrecen en el panorama de la investigación, en un afán por conceptualizar y definir los elementos fundamentales que integran el nuevo tipo de ciudad dispersa. En este sentido, las transformaciones funcionales, resultado de la modificación acaecida en la organización espacial de la producción y el empleo, de los lugares del consumo y del ocio y de los flujos territoriales, han sido determinantes para concebir un cambio intenso y definitivo en la estructura de la ciudad.

Entre los aspectos centrales a considerar al estudiar la reorganización actual de los usos del suelo, cabe mencionar diversos enfoques, según los fines y propósitos de cada investigación particular. A partir de Rhind y Hudson (1980), se han planteado, al respecto, tres perspectivas metodológicas diferentes: a) un enfoque funcional, según el cual, el uso del suelo se cartografía en función de la actividad que se desarrolle en él; de esta forma, se clasifica el suelo según su asociación con alguna de las funciones que cumplen para el hombre, en cuanto a la satisfacción de sus necesidades; b) un enfoque formal, que identifica el uso del suelo con la ocupación del mismo y el análisis se lleva a cabo a partir de determinadas características derivadas del aspecto visual de su representación: el tono, la textura, la densidad, la forma, el color, etc.; y c) un enfoque multidimensional, que supone la combinación de la funcionalidad de los usos y de las características visuales de los mismos.

En el análisis que planteamos, nos hemos decantado por la primera de las tres opciones. ¿Pero, como plantear el estudio de la estructura de la ciudad, a partir del contenido funcional de unidades espaciales elementales? Coincidimos con Ruiz Sánchez (2001), en que la ciudad puede ser contemplada como un «sistema cuya organización está basada en la integración e interacción de unidades diferentes, antagonistas y complementarias, cuyas funciones individuales y actividades, conjuntas y derivadas de la propia complementariedad, suponen la propia esencia del mismo». En el específico sistema de referencia de nuestra investigación, los elementos serían las parcelas. La parcela catastral tiene unas características diferentes en el aspecto funcional y/o en el aspecto físico, tanto desde el punto de vista cualitativo como desde el punto de vista cuantitativo. La particularidad de la misma se deriva de la posibilidad de constituir espacios multifuncionales; es decir, de integrar actividades y mezcla de usos del suelo complementarios.

Disponer de los datos geográficos (espaciales y temáticos), almacenados estructuralmente en el seno de una base de datos, vinculada a un Sistema de Información Geográfica (SIG), nos ha aportado una gran flexibilidad en el manejo de la misma, lo que nos ha permitido extraer información derivada por reelaboración de la ya existente. De esta manera, hemos obtenido la combinación de los usos del suelo existentes en cada parcela, con la intención de definir patrones taxonómicos a partir de las tipologías dominantes resultantes.

De acuerdo con el objetivo del trabajo, la primera de las tareas consistiría en la clasificación o taxonomía de los usos, mediante la desagregación y asociación de categorías resultantes de las parcelas, en función del territorio analizado. No todos los usos del suelo urbano tienen la misma representación en la ciudad. Atendiendo a su grado de implantación, 
podemos considerar la existencia de usos dominantes o característicos, de acuerdo al número de parcelas que afectan o a la superior extensión o superficie que ocupan en el territorio. De todos los usos representados en la parcela catastral, referidos con anterioridad, hemos estimado como más representativos, por la especial vinculación que tienen con el desarrollo del planeamiento urbano, los siguientes:

- El uso del suelo residencial, correspondiente al alojamiento, con carácter permanente o no, de personas y sus familias. La gran superficie de suelo ocupado por esta función urbana, además de su variedad y papel desempeñado en la estructura de la ciudad, ha sido la causa de que apreciáramos nuevas categorías más pormenorizadas dentro del mismo, como la vivienda unifamiliar y la vivienda multifamiliar.

- El uso del suelo comercial, que comprende aquellas actividades destinadas a suministrar mercancías al público, o a prestar determinados servicios a los particulares.

- El uso del suelo industrial, que tiene por finalidad llevar a cabo las operaciones de elaboración, transformación, reparación, almacenaje, y distribución de productos manufacturados.

- El uso del suelo de oficinas, que corresponde a aquellas actividades terciarias que se dirigen, como función principal, a prestar servicios de carácter administrativo, técnico, financiero, de información u otra naturaleza, realizados a partir del manejo y transmisión de información y conocimientos, bien dirigidos a las empresas y/o los particulares.

En conjunto, resultan un total de cinco categorías a considerar (uso residencial de vivienda unifamiliar, uso residencial de vivienda multifamiliar, uso comercial, uso industrial y uso de oficinas), lo que supone una notable variedad en cuanto a la desagregación de categorías se refiere. El número de posibles agrupaciones de dichas categorías, de acuerdo a la teoría combinatoria, y a su presencia real en el caso que nos ocupa, ha resultado ser de 24. Finalmente, hemos juntado el resto de usos del suelo en una única categoría. Los resultados, obtenidos mediante la realización de operaciones taxonómicas en un $\mathrm{SIG}^{8}$, de manera individualizada para los dos territorios analizados, se pueden observar en las tablas 1 y 2 .

Como puede observarse, hemos analizado, exclusivamente, las parcelas catastrales edificadas, cuyo número superaba, en ambos casos, el $80 \%$ del total de las parcelas existentes 9 . Las conclusiones más interesantes que pueden deducirse de un análisis conjunto y comparado de ambas tablas son las siguientes:

1. Los datos reflejan, como ya es habitual en este tipo de estudios, que el uso del suelo residencial supera, ampliamente, en cantidad y superficie, la representación del resto de los usos urbanos analizados.

2. El número de parcelas catastrales edificadas, de uso exclusivo, relativas a las cinco categorías de usos del suelo consideradas, suponen, para el territorio conjunto del sur

8 Para ello se ha utilizado el SIG ArcGIS, en su versión 10.1.

9 De esta manera, hemos evitado examinar aquellas parcelas en proceso de edificación, que habrían dificultado la medición de la estructura urbana de cada uno de los dos territorios considerados. 
y oeste madrileños, el 90,6\% del total existente. La distribución parcial de los mismos muestra un desigual reparto, siendo el uso residencial unifamiliar el que prevalece sobremanera respecto a los demás (74,3\% del total). A gran distancia, le seguiría el uso industrial $(8,7 \%)$, el residencial multifamiliar $(6,5 \%) \mathrm{y}$, en menor medida, el comercial $(0,8 \%)$ y de oficinas $(0,4 \%)$.

3. Esta realidad, en relación al uso residencial más extensivo, queda matizada si atendemos a su distribución espacial, al ponerse de manifiesto el gran contraste existente en el territorio madrileño $(63,2 \%$ de las parcelas de vivienda unifamiliar sobre el total edificado, en el sector sur de la Comunidad de Madrid y 82,9\% en el sector oeste). Estos valores porcentuales relativos quedan bastante reducidos, si los expresamos respecto a la superficie total ocupada, al disminuir los mismos al $10,4 \%$ y $35,4 \%$ respectivamente (1.805,4 Ha en el sur y $7.906 \mathrm{Ha}$ en el oeste).

4. El resultado de las posibles combinaciones de los usos del suelo muestra la existencia de «usos del suelo mixto», que evidencian el nivel de complementariedad o rechazo de los mismos entre sí. Relativo al tejido residencial, podemos destacar que el uso destinado a la vivienda unifamiliar posee un carácter más puro, ya que apenas se asocia con el resto de usos (el 99,6\% del total de las parcelas son de uso exclusivo residencial). En este caso, las unidades territoriales destacan por su reducida extensión superficial relativa y su condición de escasa complementariedad respecto a otros usos del suelo. Como tendremos ocasión de mostrar, su comportamiento territorial resalta la tendencia al agrupamiento con otras unidades espaciales semejantes, de tamaño muy parecido, en unidades estructurales más amplias, de morfología edificatoria similar (aislada, pareada, adosada, etc.), fruto de operaciones urbanísticas unitarias.

5. No ocurre lo mismo con el suelo residencial multifamiliar, que se agrega con gran facilidad al uso comercial (el 44,4\% de las parcelas comparten, en número, ambos usos del suelo, mientras que apenas un escaso $11,5 \%$ lo hacen con el uso industrial y/o de oficinas). Esta asociación residencia/comercio es muy superior en el sector sur $(54,3 \%)$ respecto al sector oeste $(27,1 \%)$ y es clásica, en el territorio analizado, de los cascos antiguos y ensanches residenciales que tuvieron lugar en el primer momento de la conformación metropolitana de Madrid, en los municipios más próximos a la capital.

6. El comercio constituye el uso del suelo más promiscuo y de mayor capacidad de asociación con otros usos. Su relación natural con el tejido residencial multifamiliar forma parte de nuestra cultura, estando ligado, íntimamente, a la existencia de locales artesanales o mixtos en las plantas bajas de edificios multivivienda. Sin embargo, frente al modelo comercial tradicional han surgido, en el marco del modelo de la ciudad dispersa, grandes centros comerciales de la periferia, desligados de la calle y localizados en la proximidad a las autopistas urbanas. La nueva estructura comercial agrupa no solo hipermercados, sino galerías comerciales anexas, donde se concentran boutiques y tiendas de especialidad y servicios diversos (López Lucio, 2006). En menor medida, este suelo comercial periférico no residencial se asocia a las oficinas y la industria.

7. La función industrial destaca por su carácter exclusivo y su débil capacidad de mezcla con otros usos, como corresponde a los polígonos industriales o espacios especializa- 


\begin{tabular}{|c|c|c|c|}
\hline & 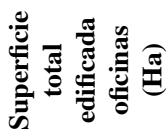 & 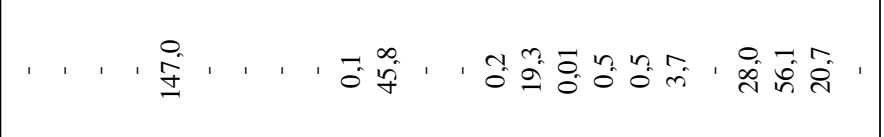 & $\frac{\infty}{\vec{\pi}}$ \\
\hline & 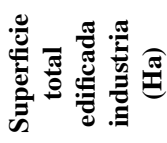 & 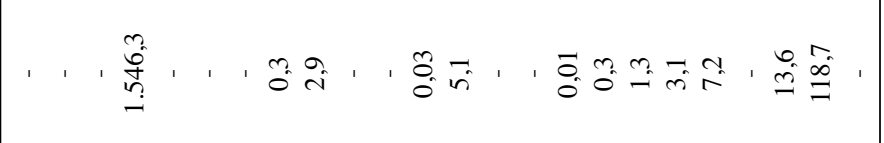 & 官 \\
\hline & 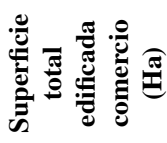 & 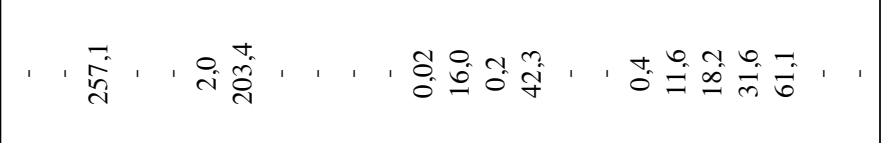 & $\begin{array}{l}0 \\
\text { fo } \\
\text { f }\end{array}$ \\
\hline$\infty \stackrel{\substack{2 \\
\frac{2}{2}}}{\frac{2}{2}}$ & 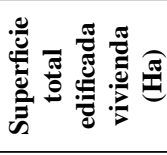 & 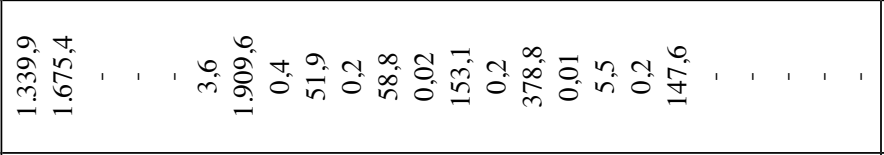 & 足 \\
\hline 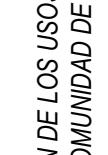 & 总 & 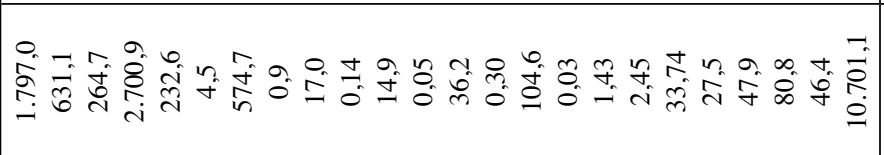 & 定 \\
\hline 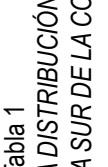 & 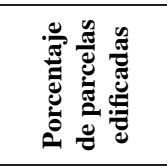 & 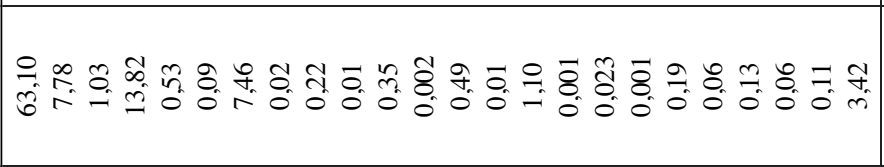 & $\begin{array}{l}8 \\
8 \\
8\end{array}$ \\
\hline 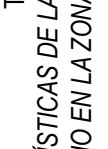 & 总 气 & 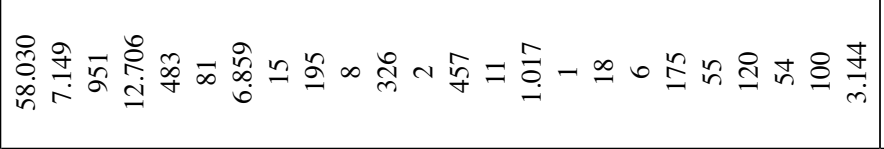 & $\frac{\hat{2}}{\stackrel{\alpha}{\alpha}}$ \\
\hline 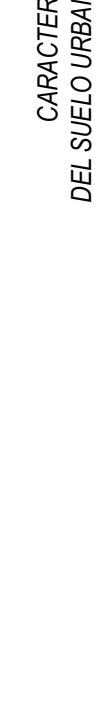 & 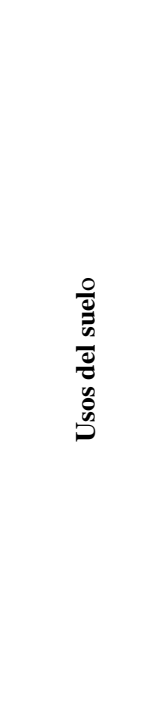 & 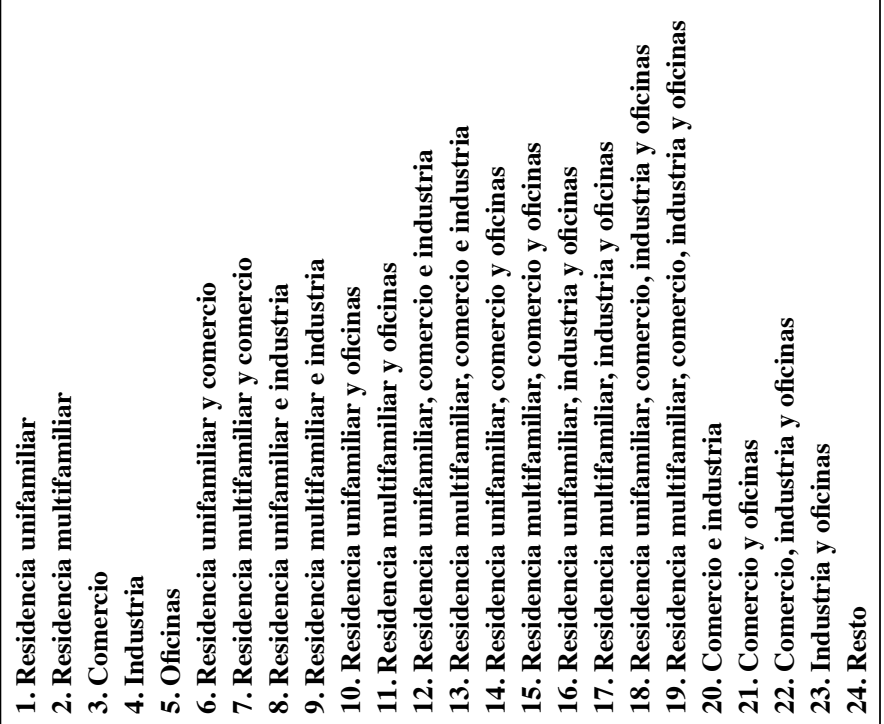 & 吾 \\
\hline
\end{tabular}




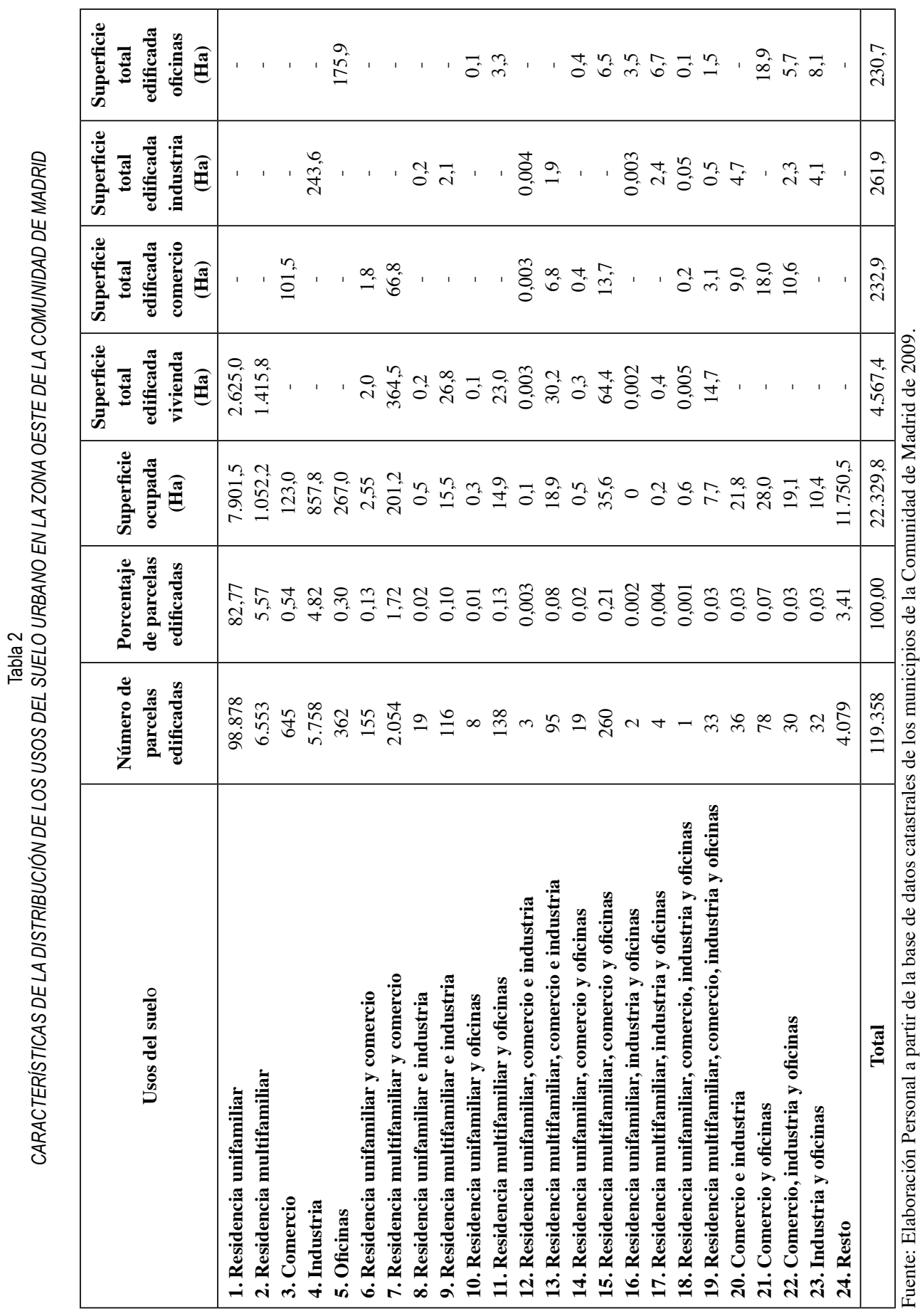


dos del territorio donde se concentra un cierto número de empresas dedicadas a este tipo de actividad. Así, en el 92,7\% del total de las parcelas edificadas, dedicadas al sector de la industria, predomina este uso exclusivo; circunstancia que puede apreciarse, tanto en el sector sur como en el oeste de la Comunidad de Madrid. Las mayores divergencias, en la distribución espacial de la actividad industrial, entre ambos sectores geográficos, pueden observarse en la mayor superficie ocupada por este uso del suelo en el sur respecto al oeste, como corresponde a la tradición manufacturera de esta área de la periferia madrileña.

8. Finalmente, podemos destacar la tendencia del uso del suelo destinado a oficinas a mezclarse con otros usos, preferentemente el uso residencial multifamiliar, el comercial y, en menor medida, el industrial. En el conjunto de ambos sectores espaciales, únicamente el $25,7 \%$ de las parcelas es de uso exclusivo, destacando la asociación con el uso multifamiliar y/o comercial $(67,9 \%$ del total). Respecto a la distribución geográfica, se pueden apreciar fuertes contrastes, ya que la tipología de uso exclusivo de oficinas es dominante en la zona oeste madrileña $(37,4 \%$ del total de parcelas) frente a la zona sur $(20,0 \%)$. Ello es la consecuencia de la aparición, en esta zona de la ciudad, de centros secundarios de oficinas que han servido para descongestionar la actividad terciaria del centro de la capital.

\section{DEFINICIÓN DE LOS PRINCIPALES PATRONES DE OCUPACIÓN TERRITORIAL DEL MODELO DE CIUDAD DISPERSA. APLICACIÓN AL SECTOR SUROESTE DE LA COMUNIDAD DE MADRID}

La propuesta de usos del suelo base, con vistas a la obtención de patrones reales de ocupación del territorio, la hemos realizado, a partir de los dos elementos utilizados en el apartado anterior: unidad territorial de análisis y categoría de uso del suelo. La unidad espacial ha sido, en nuestro caso, la parcela catastral, mientras que para las categorías de ocupación del suelo hemos seleccionado, exclusivamente, los usos más representativos. De acuerdo a este planteamiento simplificador, proponemos la siguiente categorización (tabla 3), por agrupación de clases, en la perspectiva de obtener los denominados «pre-lugares» o «espacios de vocación» (Bozzano et al., 2008).

Los pre-lugares o espacios vocacionales, pueden ser definidos como lugares en términos de patrones de ocupación y apropiación territorial, donde se identifican matices y variantes en cada vocación. Aunque no corresponden a un único uso del suelo, predomina en ellos una actividad sobre las demás. Así, por vocación residencial multifamiliar dominante se entendería el lugar donde predominaran usos y funciones destinadas a la vivienda de uso permanente o temporal de varias familias, sobre otras vocaciones, como el comercio, la industria artesanal o cualquier otra actividad que pudiera considerarse complementaria.

La reconstrucción de las unidades territoriales formales o piezas del mosaico urbano, a partir de las unidades elementales funcionales o parcelas, requiere del conocimiento preciso de los procesos acaecidos en la ciudad, ya que son éstos los que permiten interpretar los espacios conformados como una consecuencia de la dinámica del desarrollo urbano, en concordancia con las necesidades del sistema productivo, los gustos demandados por los consumidores y los avances de las nuevas tecnologías. A. Font (1997) nos ofrece una 


\begin{tabular}{|l|l|}
\hline \multicolumn{1}{|c|}{ Nuevas categorías } & \multicolumn{1}{c|}{ Categorías agrupadas } \\
\hline 1. Residencial unifamiliar exclusivo & 1 \\
2. Residencial unifamiliar dominante & $6,8,10,12,14,16$ y 18 \\
3. Residencial multifamiliar exclusivo & 2 \\
4. Residencial multifamiliar dominante & $7,9,11,13,15,17$ y 19 \\
5. Comercial exclusivo & 3 \\
6. Industrial exclusivo & 4 \\
7. Uso de oficinas exclusivo & 5 \\
8. Uso mixto (comercio, industria y oficinas) & $20,21,22$ y 23 \\
\hline
\end{tabular}

interesante perspectiva teórica desde la que plantear el reconocimiento de las nuevas formas urbanas generadas en la ciudad actual. Así, el autor distingue las siguientes unidades básicas del entramado urbano:

- Aglomerados: asentamientos urbanos, cuya característica principal es la continuidad de sus tramas, su relativa densidad y la mezcla de usos, de formación histórica o reciente.

- Extensiones de las tramas urbanas anteriores por prolongación de sus mallas viarias, generalmente de carácter más monofuncional (residencia, industria).

- Hilos o filamentos: formaciones lineales a lo largo de infraestructuras viarias históricas (carreteras o caminos) o a lo largo de elementos geográficos singulares (ríos, elementos orográficos, etc.).

- Desagregados: asentamientos en forma arbórea o en paquetes más o menos cerrados sobre topografías diversas, de carácter predominantemente residencial, aunque sean frecuentes también con el uso industrial y de almacenamiento en la segunda y tercera coronas metropolitanas.

- Asentamientos dispersos: resultado de la ocupación individualizada del territorio rústico, según una lógica autoorganizativa, aunque sin las características de marginalidad propias de épocas anteriores.

- Elementos arteriales: canales de comunicación o movilidad, que representan fundamentalmente las infraestructuras viarias y de transporte, y de los sistemas energético y de telecomunicaciones, cada vez más relevantes para la organización territorial.

- Enclaves o nodos: edificios o agrupación de edificios e instalaciones, situados en puntos estratégicos del territorio (enlaces de autopistas, intercambiadores de transporte, etc.), de máxima accesibilidad y/o significación metropolitana.

Sirviéndonos de esta referencia teórica, nos proponemos la comprobación, en el territorio del suroeste metropolitano madrileño, de la existencia de alguna de estas unidades básicas, que, a modo de ensayo, nos ofrezcan la línea a seguir en el intento de reconstruir el entramado global de la estructura de toda la urbe. 


\section{IV.1. Delimitación de algunos patrones de ocupación territorial, en el sector suroeste de la Comunidad de Madrid}

La delimitación de estas unidades territoriales no es difícil de realizar, ya que las nuevas aglomeraciones urbanas dispersas se caracterizan por la fragmentación física (además de social) del territorio, en áreas funcionales que se articulan a través del sistema de autopistas metropolitanas. La posibilidad de definirlas se apoya en los tres elementos que caracterizan la transformación territorial metropolitana más reciente: expansión, dispersión y fragmentación. El conocimiento de los procesos de transformación urbana ayuda, sobremanera, a identificar las unidades morfofuncionales de la estructura de la ciudad, que deben ser analizadas, de manera evolutiva en el tiempo, desde la expansión u ocupación cada vez más periférica del espacio (además de considerar los cambios por reforma y relleno de los intersticios vacíos de la ciudad central).

En esta perspectiva evolutiva del análisis de la estructura de la ciudad actual, debemos concentrarnos en dos momentos clave que diferencian unidades territoriales específicas. En general, las transformaciones acaecidas durante los años sesenta y setenta del pasado siglo, en el momento de conformación del área metropolitana madrileña, tuvieron como consecuencia la creación de zonas funcionalmente mixtas, en los cascos antiguos y áreas de expansión de los municipios cercanos a la ciudad central, y de áreas homogéneas en la periferia de los mismos (residenciales de alta densidad e industriales). Por otra parte, los procesos de dispersión de la ciudad, connaturales con el crecimiento urbano del momento presente, se identifican más con la existencia de áreas homogéneas residenciales de baja densidad (tanto unifamiliares como multifamiliares), nodos o enclaves del terciario o de la industria de innovación (parques tecnológicos), asentamientos industriales dispersos, grandes equipamientos y dotaciones (hospitales, universidades, parques regionales), etc. Estas unidades territoriales destacan, en general, por constituir espacios funcionales homogéneos, que consumen importantes superficies del territorio metropolitano, en un paisaje desestructurado, cuya lógica viene reflejada por la relación de las diversas piezas urbanas con la infraestructura viaria y de transporte.

En este intento de identificar y delimitar patrones de ocupación en el territorio de la Comunidad de Madrid, a modo de entramados urbanos homogéneos, siguiendo la terminología explícita de la obra antes reseñada, hemos seleccionado tres ejemplos: el barrio de Zarzaquemada, en Leganés, cuya configuración urbana tuvo lugar durante los años setenta del pasado siglo (aglomerado); el parque Európolis, situado en el municipio de Las Rozas (enclave o nodo) y la urbanización Cerro Alarcón, localizada en los municipios de Valdemorillo y Navalagamella, una de las urbanizaciones residenciales de baja densidad más extensa de la Comunidad de Madrid (desagregado).

\section{IV.1.1. El barrio de Zarzaquemada (Leganés): ciudad dormitorio de la primera corona metropolitana madrileña}

El barrio de Zarzaquemada, constituye parte de la expansión del municipio de Leganés durante los años setenta del pasado siglo (figura 3). Su desarrollo urbano ha estado ligado, por tanto, al momento del crecimiento de los municipios de la primera corona metropolitana madrileña, como consecuencia de la profunda crisis de la agricultura tradicional, motivada por la introducción de nuevas técnicas y procesos productivos, que convirtieron las áreas 
rurales en espacios de paro estructural. En estas condiciones, el fuerte contingente inmigratorio, que atraído por la oferta laboral de un mercado de trabajo expansivo llegaba a la ciudad de Madrid, tuvo que ser realojado en un tiempo récord, desencadenando procesos intensivos de ocupación del espacio que originaron cambios cualitativos en las formas y modos de producción urbana. Su elección por parte de las clases trabajadoras, como lugar de residencia, estaba justificada por la existencia de una oferta de vivienda de baja calidad y reducido coste con capacidad de atender a una demanda de escasas posibilidades económicas. El nuevo ensanche urbano fue construido sobre una superficie de $117 \mathrm{Ha}$., en bloques de pisos muy elevados, generalmente de diez alturas, alcanzando densidades de ocupación del suelo muy altas, que superaban, en ocasiones, las 300 viviendas por hectárea.

Figura 3

SITUACIÓN DEL BARRIO DE ZARZAQUEMADA EN EL MUNICIPIO DE LEGANÉS

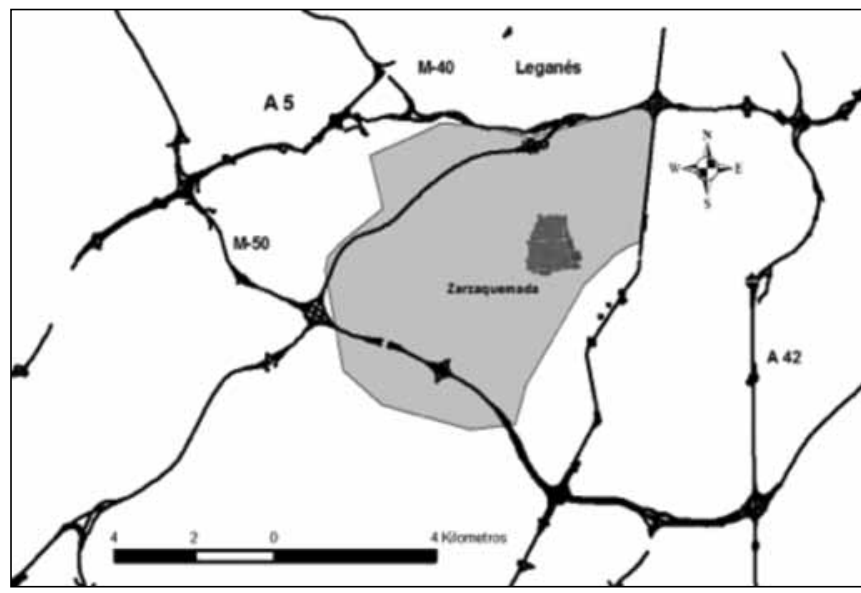

Fuente: Datos del Catastro de Urbana (2009) y Elaboración Personal.

Los resultados obtenidos de la medición de la estructura funcional de esta área ${ }^{10}$ vienen reflejados en la tabla 4 y corroboran que el barrio de Zarzaquemada presenta las características propias de los primitivos ensanches residenciales que compactaron el espacio próximo a los cascos antiguos de los municipios de la primera corona metropolitana del Sur de Madrid. En su estructura urbana, destaca el predominio funcional residencial, típico de las ciudades dormitorio de la periferia metropolitana de Madrid, con una fuerte relación con el comercio, ya que en más de la mitad de las parcelas urbanas se integran los edificios multivivienda con los establecimientos comerciales (figura 4). Se codifica así el modelo de tejido residencial multifuncional, con predominio de la vivienda como elemento más representativo, soporte de la estructura comercial tradicional basada en la calle. El reducido número de estableci-

10 Con esta intención, se ha seleccionado, a partir de la base de datos municipal, la correspondiente al barrio de Zarzaquemada, exportando la base de datos temática dBase del SIG al programa Statgraphics Centurión, donde se ha realizado un tratamiento estadístico de la información. Esta operación ha consistido en reagrupar las categorías iniciales de los usos del suelo, midiendo el número de parcelas, superficie edificada en el espacio ocupado por las nuevas categorías y promedio del número de viviendas y establecimientos productivos por parcela. 
mientos comerciales por parcela urbana $(2,6)$ y su limitado tamaño medio $\left(64,3 \mathrm{~m}^{2}\right)$ ponen en evidencia la ausencia de concentración comercial en centros autónomos de mayores dimensiones. Así mismo, aunque en un segundo plano, apreciamos otras formas de integración de la función residencial con otras actividades a ella asociadas, como el pequeño terciario de oficinas ó servicios personales, los talleres de reparación ó los pequeños equipamientos, aunque, como puede observarse por la superficie edificada, escasamente representadas.

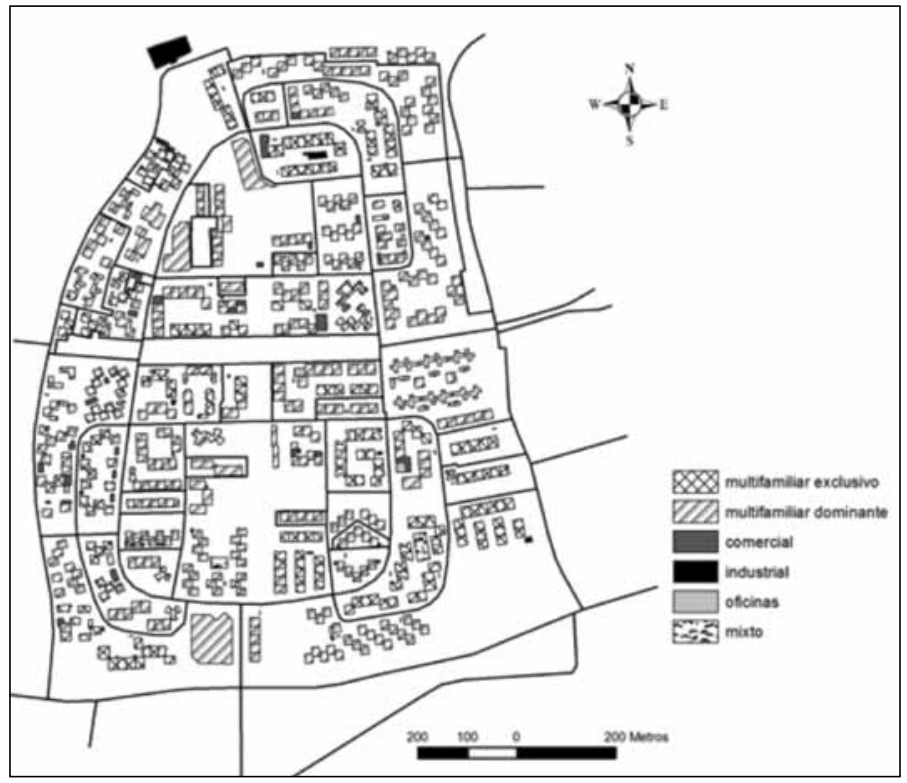

Fuente: Datos del Catastro de Urbana (2009) y Elaboración Personal.

Tabla 4

CARACTERISTIICAS FUNCIONALES DEL BARRIO DE ZARZAQUEMADA (LEGANÉS)

\begin{tabular}{|c|c|c|c|c|c|c|}
\hline \multirow{2}{*}{ Uso suelo } & \multicolumn{2}{|c|}{ Parcelas } & \multicolumn{4}{c|}{ Uso suelo edificado (Ha) } \\
\cline { 2 - 7 } & número & porcentaje & residencial & comercial & industrial & oficinas \\
\hline $\mathbf{3}$ & 239 & 32,4 & 55,9 & - & - & - \\
$\mathbf{4}$ & 389 & 52,8 & 93,0 & 6,6 & 0,04 & - \\
$\mathbf{5}$ & 38 & 5,2 & - & 0,6 & - & 0,8 \\
$\mathbf{6}$ & 61 & 8,3 & - & - & 0,3 & - \\
$\mathbf{7}$ & 4 & 0,5 & - & - & - & 0,08 \\
$\mathbf{8}$ & 6 & 0,8 & - & 0,3 & 0,2 & 0,01 \\
\hline
\end{tabular}

1. Residencial unifamiliar exclusivo; 2. Residencial unifamiliar dominante; 3. Residencial multifamiliar exclusivo; 4. Residencial multifamiliar dominante; 5. Comercial exclusivo; 6. Industrial exclusivo; 7. Uso de oficinas exclusivo; 8. Usos mixtos (comercio, industria y oficinas).

Fuente: Elaboración Personal. Datos de los municipios del Catastro de Urbana de la Comunidad de Madrid (2009). 


\section{IV.1.2. El parque de Európolis (Las Rozas)}

El parque Európolis es un espacio comercial mixto, situado en el municipio de Las Rozas (figura 5), a veinte kilómetros del centro de Madrid, localizado en un nudo de comunicaciones preferente, al que se puede acceder desde tres carreteras principales: la autovía A6 Madrid-La Coruña, la M-50 y la carretera M-505. Consta de más de 800 locales, en un entramado de treinta calles, dedicadas a múltiples actividades, no solo comerciales, sino industriales y de oficinas. Las dimensiones de las parcelas comerciales exclusivas $\left(1.582 \mathrm{~m}^{2}\right.$ de promedio de superficie edificada) superan al correspondiente a las parcelas industriales $\left(1.000 \mathrm{~m}^{2}\right)$ y las destinadas a oficinas $\left(320 \mathrm{~m}^{2}\right)$, aunque son más reducidas en número. Las actividades allí desarrolladas son muy variadas y están relacionadas con las necesidades del hogar y la empresa, mobiliario y decoración, automoción, ocio, alimentación, construcción, servicios, etc., lo que convierte al mismo en uno de los mayores centros comerciales y de negocios de la zona oeste de Madrid (figura 6). Este parque constituye un ejemplo de cómo los centros comerciales se han convertido en una pieza clave de los nuevos desarrollos periféricos de las áreas metropolitanas. Su estructura productiva gira en torno a un modelo donde existen grandes espacios abiertos y zonas verdes, con escasa diversificación de usos de suelo, su desconexión de la calle, en cuanto a espacio residencial vivido, y su anclaje en la autopista.

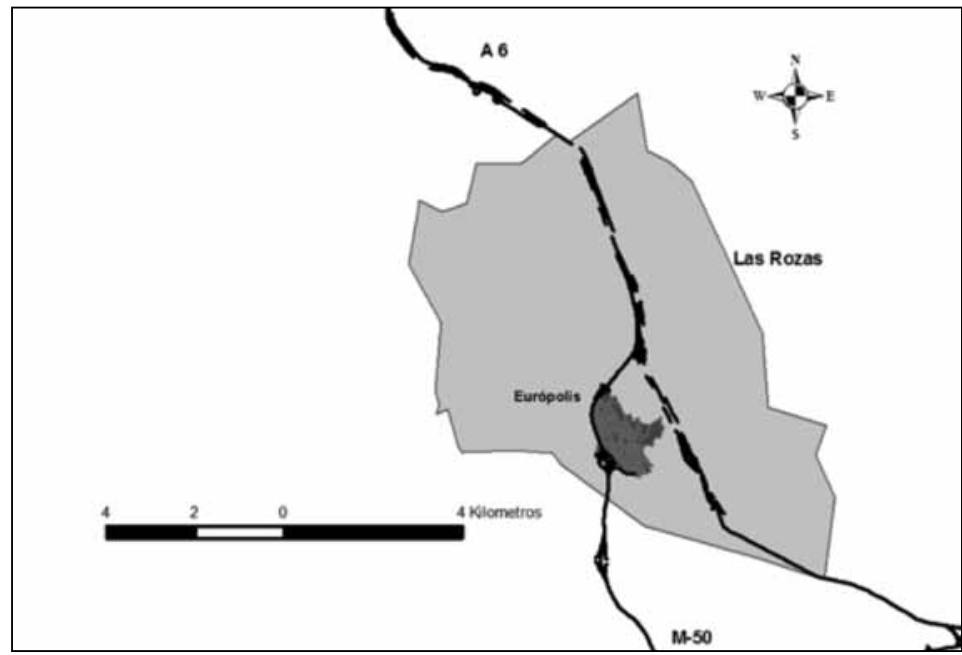

Fuente: Datos del Catastro de Urbana (2009) y Elaboración Personal.

Otra característica es la de su diáfana distinción de los usos residenciales o su especialización residencial (oferta de vivienda), separada de la anterior. En este sentido, contigua a la zona productiva existe un área residencial (zona A), segregada de la anterior (zona B), e integrada por viviendas multifamiliares de alto estanding, con zonas ajardinadas y piscina, 
en un entramado regular en manzana, con reducida densidad de ocupación del suelo. Las posibilidades de instalación de servicios y pequeños comercios de proximidad se muestran complicadas en estas áreas residenciales, por la existencia de tendencias hacia estructuras edificatorias con espacios de esparcimiento privado, sin la posibilidad de ubicación de actividad comercial en sus plantas bajas. Todo ello queda reflejado en la escasa presencia de espacio edificado dedicado a la industria y los servicios.

Figura 6

DISTRIBUCIÓN ESPACIAL DE LOS USOS DEL SUELO DEL PARQUE

DE EURÓPOLIS EN EL MUNICIPIO DE LAS ROZAS

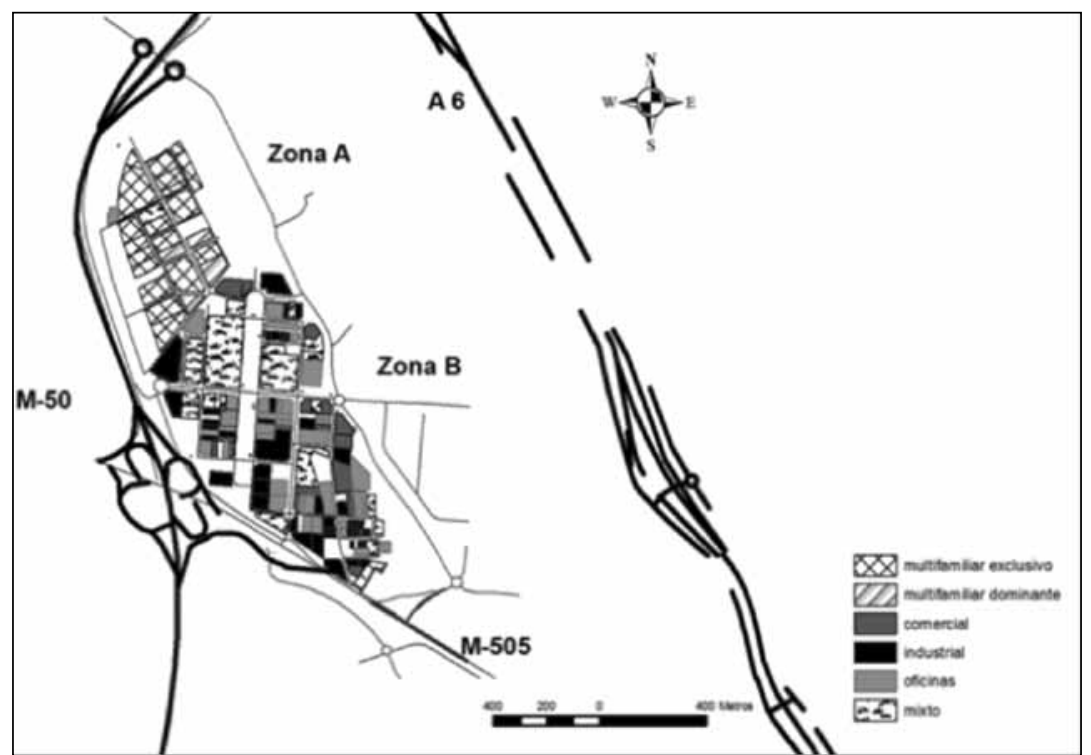

Fuente: Datos del Catastro de Urbana (2009) y Elaboración Personal.

Tabla 5

CARACTERÍSTICAS FUNCIONALES DEL PARQUE EURÓPOLIS (LAS ROZAS) (ZONAA)

\begin{tabular}{|c|c|c|c|c|c|c|}
\hline \multirow{2}{*}{$\begin{array}{c}\text { Uso } \\
\text { suelo }\end{array}$} & \multicolumn{2}{|c|}{ Parcelas } & \multicolumn{4}{c|}{ Uso suelo edificado (Ha) } \\
\cline { 2 - 7 } & número & porcentaje & residencial & comercial & industrial & oficinas \\
\hline $\mathbf{3}$ & 19 & 61,3 & 2,6 & - & - & - \\
$\mathbf{4}$ & 5 & 16,1 & 3,8 & 0,4 & - & 0,01 \\
$\mathbf{6}$ & 8 & 25,8 & - & - & 0,01 & - \\
$\mathbf{7}$ & 1 & 3,2 & - & - & - & 0,6 \\
\hline
\end{tabular}

1. Residencial unifamiliar exclusivo; 2. Residencial unifamiliar dominante; 3. Residencial multifamiliar exclusivo; 4. Residencial multifamiliar dominante; 5. Comercial exclusivo; 6. Industrial exclusivo; 7. Uso de oficinas exclusivo; 8. Usos mixtos (comercio, industria y oficinas).

Fuente: Elaboración Personal. Datos de los municipios del Catastro de Urbana de la Comunidad de Madrid (2009). 
Tabla 6

CARACTERISTIICAS FUNCIONALES DEL PARQUE EURÓPOLIS (LAS ROZAS) (ZONAB)

\begin{tabular}{|c|c|c|c|c|c|c|}
\hline \multirow{2}{*}{ Uso suelo } & \multicolumn{2}{|c|}{ Parcelas } & \multicolumn{4}{c|}{ Uso suelo edificado (Ha) } \\
\cline { 2 - 7 } & número & porcentaje & residencial & comercial & industrial & oficinas \\
\hline $\mathbf{3}$ & 1 & 0,7 & 0,3 & - & - & - \\
$\mathbf{5}$ & 19 & 13,4 & - & 4,9 & - & - \\
$\mathbf{6}$ & 64 & 45,1 & - & - & 8,0 & - \\
$\mathbf{7}$ & 37 & 26,0 & - & - & - & 9,5 \\
$\mathbf{8}$ & 21 & 14,8 & - & 5,4 & 1,6 & 4,4 \\
\hline
\end{tabular}

1. Residencial unifamiliar exclusivo; 2. Residencial unifamiliar dominante; 3. Residencial multifamiliar exclusivo; 4. Residencial multifamiliar dominante; 5. Comercial exclusivo; 6. Industrial exclusivo; 7. Uso de oficinas exclusivo; 8. Usos mixtos (comercio, industria y oficinas).

Fuente: Elaboración Personal. Datos de los municipios del Catastro de Urbana de la Comunidad de Madrid (2009).

\section{IV.1.3. La urbanización residencial del Cerro Alarcón (Valdemorillo y Navalagamella)}

La urbanización del Cerro Alarcón nació hace más de treinta años como un espacio de recreo y chalets de fin de semana, enclavada en los municipios de Valdemorillo y Navalagamella (figura 7), habiéndose convertido, hoy en día, en una comunidad de más de 1.000 propietarios, la mayor parte de los cuales viven allí de forma permanente. Su entorno natural, de grandísimo valor medioambiental, Zona Especial de Protección de Aves y Lugar de Importancia Comunitaria de los Encinares y Cuencas de los ríos Alberche y Cofio, se encuentra en un excepcional estado de conservación. Se han respetado la mayor parte de las encinas originarias y, al mismo tiempo, los jardines privados han dado lugar a una masa arbórea de gran diversidad, en la que destacan todo tipo de coníferas, chopos y enebros, que constituyen un microclima propio de mayor humedad y frescor. En la urbanización está integrado el embalse de Cerro Alarcón, que la promotora construyó en los años setenta del siglo pasado como valor añadido, al permitir la práctica de deportes. El diseño de la urbanización está basado en grandes avenidas y parcelas que oscilan entre los 900 y 1.100 metros cuadrados, lo que ha permitido la construcción de chalets independientes con jardines y piscina propia en la mayor parte de los casos y una red de zonas verdes que incrementa los espacios y permite mayor calidad de vida.

Las características funcionales de la urbanización (tabla 7) muestran el predominio, casi exclusivo, de la función residencial de baja densidad, con viviendas unifamiliares, cuya participación supera el $98 \%$ en el número de parcelas existentes. Así mismo, la vivienda unifamiliar consume más del $99 \%$ de la superficie edificada, respecto a los otros usos del suelo allí representados, debido a las mayores necesidades de suelo que la vivienda unifamiliar representa en relación con la plurifamiliar o en bloque. Esta realidad manifiesta una de las propiedades del espacio residencial extensivo, en el que progresivamente se ha ido clausurando la mezcla con otros usos, haciéndose más excluyente y, como consecuencia, más dependiente del transporte mecanizado para cualquiera de sus relaciones con el exterior (trabajo, compras, diversión). 
Figura 7

SITUACIÓN DE LA URBANIZACIÓN CERRO DE ALARCÓN

EN LOS MUNICIPIOS DE VALDEMORILLO Y NAVALAGAMELLA

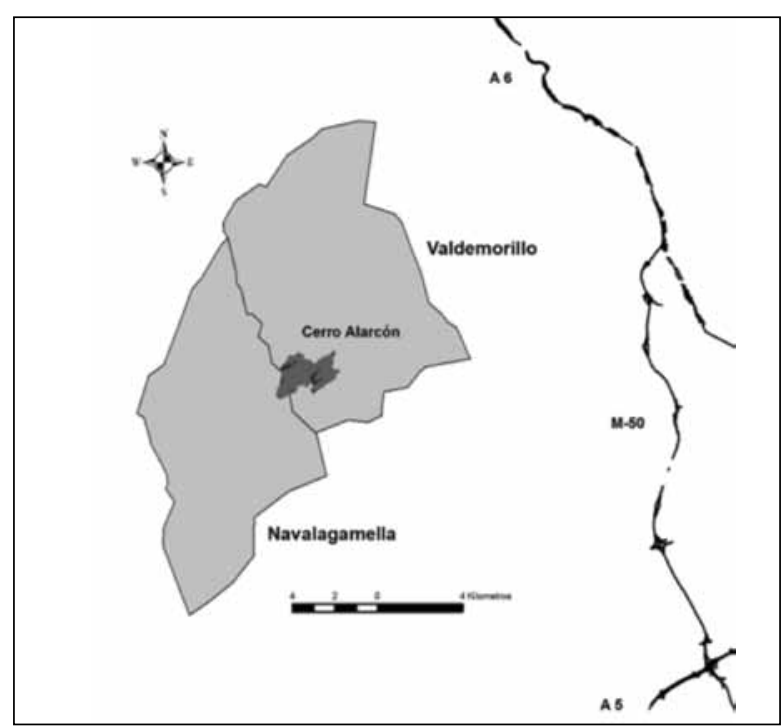

Fuente: Datos del Catastro de Urbana (2009) y Elaboración Personal.

Figura 8

DISTRIBUCIÓN ESPACIAL DE LOS USOS DEL SUELO DE LA URBANIZACIÓN CERRO DE ALARCÓN EN LOS MUNICIPIOS DE VALDEMORILLO Y NAVALAGAMELLA

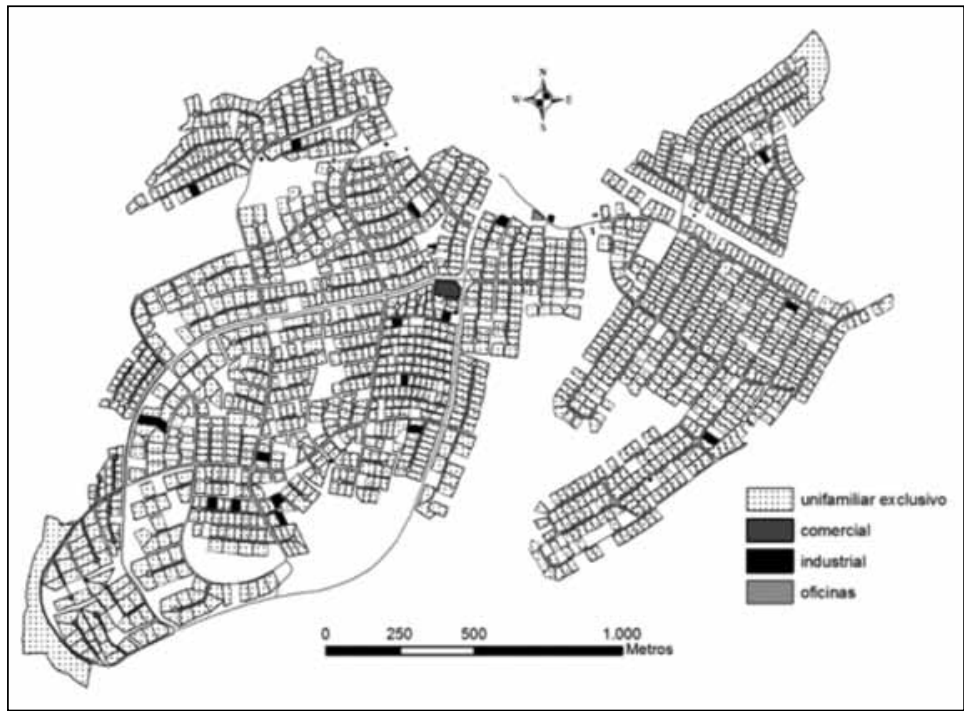

Fuente: Datos del Catastro de Urbana (20009) y Elaboración Personal. 
Tabla 7

CARACTERISTICAS FUNCIONALES DEL PARQUE EURÓPOLIS (VALDEMORILLO Y NAVALAGAMELLA)

\begin{tabular}{|c|c|c|c|c|c|c|}
\hline \multirow{2}{*}{ Uso suelo } & \multicolumn{2}{|c|}{ Parcelas } & \multicolumn{4}{c|}{ Uso suelo edificado (Ha) } \\
\cline { 2 - 7 } & número & porcentaje & residencial & comercial & industrial & oficinas \\
\hline $\mathbf{1}$ & 1.728 & 98,1 & 40,4 & - & - & - \\
$\mathbf{5}$ & 1 & 0,06 & - & 0,06 & - & - \\
$\mathbf{6}$ & 32 & 1,8 & - & - & 0,14 & - \\
$\mathbf{7}$ & 1 & 0,06 & - & - & - & 0,0025 \\
\hline
\end{tabular}

1. Residencial unifamiliar exclusivo; 2. Residencial unifamiliar dominante; 3. Residencial multifamiliar exclusivo; 4. Residencial multifamiliar dominante; 5. Comercial exclusivo; 6. Industrial exclusivo; 7. Uso de oficinas exclusivo; 8. Usos mixtos (comercio, industria y oficinas).

Fuente: Elaboración Personal. Datos de los municipios del Catastro de Urbana de la Comunidad de Madrid (2009).

\section{CONCLUSIONES}

La utilización del catastro de urbana en el estudio del territorio ofrece nuevas perspectivas de gran interés, en fines tan diversos como la valoración de su problemática, la cartografía o representación del mismo, y, finalmente, la ordenación y planificación territorial. Su trascendencia como tal se deriva de la capacidad de la parcela urbana, para integrar, en un espacio físico reducido, un conjunto de elementos clave para interpretar la ciudad, desde la perspectiva de identificar la lógica de los fenómenos del crecimiento urbano. En nuestro caso, la metodología desarrollada a partir de usos del suelo urbano, incluidos con carácter multifuncional, muestra la posibilidad de analizar cuantitativamente la estructura de nuestras urbes, de manera evolutiva en el tiempo, permitiendo realzar los profundos contrastes existentes entre la ciudad compacta del pasado y la ciudad dispersa actual, a partir del mosaico urbano y las piezas funcionales asociadas a cada una de los espacios de actividad, consumo y ocio que lo integran.

El estudio de tres casos concretos de la estructura urbana del sector suroeste metropolitano madrileño, de origen diferente, nos ha permitido mostrar el camino para la obtención de la estructura urbana de la Comunidad de Madrid, a nivel más global, a la par que descubrir algunos aspectos fundamentales, relacionados con el cambio de modelo de ciudad. Así, frente al entrelazamiento de las funciones residencial y de actividad que se daba en la ciudad tradicional (cuyo arquetipo representativo sería el barrio de Zarzaquemada), donde la zonificación de usos respetaba la continuidad del tejido urbano, en las nuevas periferias, las áreas residenciales y el resto de actividades ocupan sectores segregados, donde, además, se introduce la discontinuidad entre los distintos fragmentos especializados. En este marco de referencia, los centros comerciales, como el parque de Európolis, «alimentan la denominada ciudad dispersa, convirtiéndose en pieza clave de estos complejos desarrollos suburbanos, contribuyendo a la desaparición de las diferencias entre el centro tradicional y la periferia, al trasladar o dispersar y al mismo tiempo concentrar las funciones de consumo y ocio en espacios cada vez más periurbanos» (Escudero, 2008). El otro ejemplo, el de la urbanización del Cerro de Alarcón, revela el aislamiento de los paquetes residenciales de baja densidad, auténticas islas conectadas a las infraestructuras y ancladas a ellas, pero separadas entre sí 
física y socialmente. En este sentido, la vivienda unifamiliar tiende a homogenizar los paisajes, reducir las densidades metropolitanas y acrecentar una cada vez mayor fragmentación espacial, que en algunos ámbitos se traduce, incluso, en la propia privatización del espacio.

Finalmente, queremos subrayar la importancia que la metodología propuesta puede tener en su potencial aplicación en el campo de la planificación medioambiental y territorial. En primera instancia, al mostrar como el empleo de nuevas bases de datos georreferenciados podría suponer un importante avance en la construcción y disponibilidad de bases de datos geográficas más relacionadas con la complejidad del mundo real, capaces de acometer los problemas de la planificación territorial, en un entorno SIG, desde un enfoque más realista y eficaz. En segundo lugar, por la posibilidad de disponer de la estructura funcional de la ciudad, de forma sintética y simplificada, pero suficientemente representativa de la realidad, desde donde plantearse diferentes objetivos de investigación: generación de escenarios de futuro en zonas afectadas por el crecimiento urbano actual, simulación de modelos realistas del desarrollo urbano en el futuro o evaluación de impactos sobre los recursos naturales y medioambientales de un territorio determinado y de su población residente.

\section{REFERENCIAS}

BOZZANO, H., CARUT, C., BARBETTI, G. C. y ARRIVILlAGA, N. (2008): «Usos del suelo y lugares: criterios teórico-metodológicos. Aplicación a un caso en Guatemala», Revista Universitaria de Geografía (on line), $\mathrm{n}^{\circ}$ 17, pp. 189-231.

DE SANTIAGO RODRÍGUEZ, E. (2008): «Nuevas formas y procesos espaciales en el territorio contemporáneo: la «ciudad única», Polis, vol 7, n 20. Editorial de la Universidad Bolivariana, Chile, pp. 53-71.

DEMATTEIS G. (1998): «Suburbanización y periurbanización. Ciudades anglosajonas y ciudades latinas», en La ciudad dispersa: suburbanización y nuevas periferias, F. J. Monclús (Ed.). Centro de Cultura Contemporánea. Barcelona, pp. 5-15.

ESCUDERO GÓMEZ, L.A. (2008): Los centros comerciales. Espacios postmodernos de ocio y consumo. Ediciones de la Universidad de Castilla-La Mancha, Colección Monografías, Cuenca, 249 páginas.

FERRÁS SEXTO, C. (2000): «Ciudad dispersa, aldea virtual y revolución tecnológica. Reflexión acerca de sus relaciones y significado social», Scripta Nova, Revista Electrónica de Geografía y Ciencias Sociales. Disponible en http://www.ub.es/geocrit/sn-69-68. htm. Universidad de Barcelona.

FONT, A. (1997): «Anatomía de una metrópoli discontinua: la Barcelona metropolitana», Papers, Región Metropolitana de Barcelona, n² 26, pp. 9-19, Barcelona.

FONT, A., LLOP, C. Y VILANOVA, J. M. (1999): La construcción del territorio metropolitano. Morfogénesis de la región urbana de Barcelona, Barcelona: Mancomunitat Metropolitana de Municipis, 211 páginas.

GUIMET PEREÑA, J. (2003): Descripción y teoría general del catastro. Ediciones UPC, Barcelona.

GUTIÉRREZ PUEBLA, J. y GARCÍA PALOMARES, J. C. (2007): «Espacios residenciales en la ciudad dispersa», en Homenaje al profesor Casas Torres. Universidad Complutense, pp. 445-456, Madrid. 
LAVASTRE, P. y MÁS, R. (Coords.) (2005): Propiedad urbana y crecimiento de la ciudad. Ediciones de la Universidad Autónoma de Madrid, Madrid.

LÓPEZ LUCIO, L. (2006): «Espacio público e implantación comercial en la ciudad de Madrid», en Cuadernos de investigación urbanística. Número 23, Madrid, pp 1-48.

MÁS MAYORAL, S. (2009): «El cambio de paradigma de la cartografía. De la cartografía al servicio del poder a la interoperabilidad de los servicios de información geográfica». Revista Catastro, $\mathrm{n}^{\circ}$ 64, pp 7-35.

MONCLÚS, F.J. (1998): La ciudad dispersa. Centro de Cultura Contemporánea de Barcelona, Barcelona, 223 páginas.

RHIND, D. Y HUDSON, R (1980): Land Use. Methuen, Nueva York.

RUIZ SÁNCHEZ, J. (2001): «Sistemas Urbanos Complejos. Acción y Comunicación», en Cuadernos de Investigación Urbanística. Escuela Técnica Superior de Arquitectura. Madrid.

SERENO ÁLVAREZ,A. (2009): «La información geográfica en España: especial referencia a la cartografía catastral». Revista Catastro, $\mathrm{n}^{\circ}$ 67, pp. 31-53.

URTEAGA, L. (2008): «Dos décadas de investigación sobre la historia de la cartografía catastral en España (1988-2008)». Revista Catastro, nº 63, pp. 7-30. 